stock of King Edward used by Salaman and Le Pelley ${ }^{4}$ may have contained both viruses $S$ and $M$, although, of course, stocks at the National Institute of Agricultural Botany and those in the United States could have picked up virus $S$ at a later date.

We should also like to take this opportunity of saying that in our previous communication ${ }^{1}$ we have misinterpreted Bagnall, Wetter and Larson ${ }^{5}$. Although they state that "evidence now indicates that paracrinkle is for all practical purposes a synonym of leaf-rolling mosaic, and that both of these diseases are incited by complexes of virus $S$ and virus $M$ ", Dr. Wetter has pointed out to us that in other parts of their paper they leave it undecided as to the parts played by the two viruses in causing paracrinkle and leaf-rolling mosaic symptoms.

H. W. Howard

J. WAINWRIGHT

Plant Breeding Institute,

Trumpington,

Cambridge.

${ }^{1}$ Howard, H. W., and Wainwright, J., Nature, 186, 993 (1960).

${ }^{2}$ Howard, H. W., Genetica, 30, 278 (1959).

${ }^{3}$ Bagnall, R. H., Larson, R. H., and Walker, J. C., Res. Bull. Wis. Agric. Exp. Sta., 198 (1956).

' Salaman, R. N., and Le Pelley, R. H., Proc. Roy. Soc., B, 106, 140 $(1930)$.

Bagnall, R. H., Wetter, C., and Larson, R. I1., Phytopath., 49, 435 $(1959)$.

\section{Influence of a Quaternary Ammonium Salt on the Infectivity of Ribonucleic Acid from Tobacco Mosaic Virus}

In a previous paper, some of us ${ }^{1}$ have shown that the quaternary ammonium salts of deoxy - and ribonucleic acids are soluble in organic solvents, and that by the addition of a concentrated solution of sodium chloride a precipitate of the sodium salt of the nucleic acids is obtained. It seemed interesting to us to know if the preliminary treatment of a viral ribonucleic acid with a quaternary ammonium salt produces a structural modification which can be demonstrated by the disappearance of the infectivity of the ribonucleic acid.

Ribonucleic acid preparations were obtained from tobacco mosaic virus by the phenol method of (xierer and Schramm ${ }^{2}$. The solutions in $0.01 M$ phosphate contain about $0 \cdot 3$ per cent ribonucleic acid. The infectivity of these preparations was tested by counting the number of lesions produced on Nicotiana glutinosa. At the same time the following controls were made on the solutions : measurement of the sedimentation constant, determination of the molecular weight by light-scattering, serological control of the absence of viral proteins.

Simultaneously, one volume of the solution of ribonucleic acid from tobacco mosaic virus was divided into two parts; an equal volume of 0.2 per cent cetyl-trimethyl-ammonium bromide was added to each part; the precipitates of the ammonium salts of ribonucleic acid were washed three times by centrifuging their suspensions in water. Then, one of the samples was dissolved in absolute ethanol and the other one in dimethylformamide. The ribonucleic acid was precipitated in both solutions by $3 M$ sodium chloride and dissolved in $0.01 M$ phosphate. The concentration of these solutions was determined by measurements of the optical density at $260 \mathrm{m \mu}$ with a Jobin-Yvon spectrophotometer. The infec-

\begin{tabular}{|c|c|c|c|c|c|c|}
\hline \multirow[b]{2}{*}{ Experiment } & \multicolumn{3}{|c|}{$\begin{array}{l}\text { No. of lesions } \\
\text { per } 25 \text { leaves }\end{array}$} & \multicolumn{3}{|c|}{$\begin{array}{l}\text { Concentration of } \\
\text { ribonucleic acid } \\
\text { (mgm. per ml.) }\end{array}$} \\
\hline & 1 & 2 & 3 & 1 & 2 & 3 \\
\hline Ribonucleic acid control & 350 & 166 & 530 & $1 \cdot 00$ & $1 \cdot 13$ & $1 \cdot 19$ \\
\hline $\begin{array}{l}\text { ethanol solution } \\
\text { Ribonucleic acid from }\end{array}$ & 369 & 140 & 350 & $1 \cdot 04$ & $1 \cdot 03$ & $0 \cdot 58$ \\
\hline solution & 118 & 118 & 270 & $1 \cdot 04$ & $0 \cdot 81$ & 0.96 \\
\hline
\end{tabular}

tivity tested by the lesions produced on $N$. glutinosa in both cases was compared with the infectivity of the original solution. The results are given Table 1 .

It was found that $1 \mathrm{ml}$. of each solution incubated at $4^{\circ} \mathrm{C}$. during $10 \mathrm{~min}$. with $2 \mu \mathrm{gm}$. ribonuclease gives no lesions on the host.

The present results show that precipitation of the tobacco mosaic virus ribonucleic acid as a quaternary ammonium salt, its solubilization in ethanol or dimethylformamide and its regeneration as a sodium salt do not destroy its infectivity. However, it can be seen that although the infectivity is not signific. antly altered after treatment with ethanol, it seems to be lowered after the treatment with dimethylformamide.

These results seem to be in general agreement with those obtained by Guerritore ${ }^{3}$ on the effect of cetyltrimethyl-ammonium bromide on the infectivity of aqueous extracts of Rous sarcoma.

\section{LEON HIRTH \\ Geneviève Lebeurier}

Institut de Botanique,

Faculté des Sciences, Strasbourg.

Ganevitive Aubel-Sadron

GISÈLE BECK

Jean-Pierre Ebel

Laboratoire de Chimie Biologique,

Faculté de Pharmacie,

Strasbourg.

PAUl HorN

Centre de Recherches sur les

Macromolécules, Strasbourg.

${ }^{1}$ Aubel-Sadron, G., Beck, (x., Ebel, J. P., and Sadron, Ch., Biochim. Biophys. Acta, 42, $542(1960)$

${ }^{2}$ Gierer, A., and Schramm, G., Z. Nuturforsch., 11b, 2 (1956).

${ }^{3}$ Guerritore, D., Nature, 181, 419 (1958).

\section{MISCELLANY}

\section{A New Shadowing Material for Electron Microscopy}

THE high resolving power of electron microscopes at present available makes the granularity of metalshadowing media the limiting factor in the observation of extremely fine details of surface topography in shadowed specimens.

Platinum has probably been used more widely than any other metal because its high melting point and chemical inertness result in a very stable film. It does, however, have one disadvantage in that it forms a crystalline film which tends to appear granular at high magnification. When a platinumshadowed specimen is examined at magnifications higher than about $\times 40,000$, the image is seen to consist of many small opaque spots. While this 